\title{
JUVENTUDES POPULARES: DECENCIA, CONTRACULTURA Y MILITANCIA EN EL ESTALLIDO SOCIAL DE OCTUBRE ${ }^{1}$
}

\author{
NiCOLÁS ANGELCOS ${ }^{2}$ \\ ANDREA ROCA ${ }^{3}$ \\ EMILIA CUADROS ${ }^{4}$
}

\begin{abstract}
RESUMEN
El artículo discute los hallazgos de una investigación sociológica en curso sobre participación política en barrios estigmatizados del Gran Santiago. A diferencia de las imágenes de apatía, rabia e inactivismo político, en lo que sigue, recuperamos las experiencias, significados y expectativas en torno al Estallido Social entre jóvenes con estudios superiores y experiencia en organizaciones culturales, religiosas y políticas de base. Analíticamente, identificamos tres criterios de inteligibilidad -decencia, contracultura y militancia - que permiten comprender los modos en que los jóvenes populares narran sus vidas, describen sus barrios y relatan las experiencias vividas en las protestas y el proceso constituyente.
\end{abstract}

PALABRAS CLAVE: PARTICIPACIÓN POLÍTICA JUVENIL, SECTORES POPULARES, REVUELTA.

1 Fuentes de financiamiento: ANID / FONDECYT/11190211 y ANID / FONDAP/15130009.

${ }^{2}$ Doctor en Sociología de la École des Hautes Études en Sciences Sociales de París. Académico Universidad Andrés Bello y Universidad de Chile. Investigador asociado, Centro de Estudios de Conflicto y Cohesión Social. Correo electrónico: nicolas.angelcos@unab.cl

${ }^{3}$ Doctora en Sociología por la Universidad de São Paulo. Académica Universidad de Chile y Universidad Alberto Hurtado. Correo electrónico: aroca@uahurtado.cl

4 Estudiante de Sociología de la Universidad de Chile. Correo electrónico: emilia.cuadros@ug.uchile.cl 


\title{
JUVENTUDES POPULARES: DECÊNCIA, CONTRACULTURA E MILITÂNCIA NO SURTO SOCIAL DE OUTUBRO
}

\begin{abstract}
RESUMO
$\mathrm{O}$ artigo discute as descobertas de uma pesquisa sociológica em andamento sobre a participação política nos bairros estigmatizados do Grande Santiago. Ao contrário das imagens de apatia, raiva e desinteresse político, a seguir, recuperamos as experiências, significados e expectativas em torno do Surto Social entre jovens com ensino superior e experiência em organizações culturais, religiosas e políticas de base. Analiticamente, identificamos três critérios de inteligibilidade - decência, contracultura e militância que permitem compreender as formas em que os jovens populares narram suas vidas, descrevem seus bairros e contam as experiências vividas nos protestos e no processo constituinte.
\end{abstract}

PALAVRAS-CHAVE: PARTICIPAÇÃO POLÍTICA JUVENIL, SETORES POPULARES, REVOLTA.

\section{WORKING-CLASS YOUNG PEOPLE: DECENCY, COUNTERCULTURE AND AFFILIATION IN THE OCTOBER SOCIAL OUTBREAK}

\begin{abstract}
The article discusses the findings of an in-progress sociological research on political participation within stigmatized neighborhoods of Greater Santiago. Unlike the images of anger, apathy and political disinterest from where they are usually portrayed, we retrieve the experiences, meanings and expectations towards the Social Outbreak among young people with higher education and experienced in intrinsically cultural, religious and political organizations. Analytically, we identify three intelligibility criteria decency, counterculture, and affiliation - in order to understand the ways in which young people from working-class narrate their lives, describe their own neighborhoods, and speak about the experiences lived in protests and during the constitutional process.
\end{abstract}

KEYWORDS: YOUTH POLITICAL PARTICIPATION, WORKING-CLASS NEIGHBORHOODS, RIOT. 


\section{INTRODUCCIÓN}

Desde la recuperación de la democracia en 1990, se ha destacado una disminución significativa de la participación electoral en Chile, especialmente entre los jóvenes. A partir de esta evidencia, se construyó un imaginario social en el cual estos fueron percibidos como despolitizados, apáticos o desafectados políticamente, representando una amenaza para el desarrollo de la institucionalidad democrática (Aguilera y Muñoz, 2015). Sin embargo, a partir de la experiencia de la Revolución Pingüina de 2006, se ha planteado que, más que estar desinteresados en la política, los jóvenes expresan un sentimiento de hostilidad hacia las instituciones políticas formales, actitud que se ve compensada por una mayor participación en actividades políticas contenciosas (Venegas, 2016). Este diagnóstico es consistente con la literatura internacional que destaca un cambio en los patrones de participación política en las principales democracias del mundo, donde, junto a la disminución de la participación electoral, se observa un incremento de las prácticas políticas no convencionales como protestas, firma de peticiones, «consumo político» y activismo por internet (Cammaerts et al., 2014; Kitanova, 2019).

Sin embargo, este incremento en la participación política no convencional, sobre todo, entre jóvenes intensificaría la brecha participativa entre individuos de distinto estatus socioeconómico (Dalton, 2017). Las formas no electorales de participación requerirían de mayores recursos y habilidades, especialmente, de capital cultural (Verba, Schlozman y Brady, 1995). Sumado a estos factores individuales, desde los estudios urbanos se ha destacado cómo la urbanización neoliberal y la retirada del Estado de bienestar habrían impactado en la consolidación de la economía ilegal y una «cultura de calle» (Bourgois, 1995 ) en las periferias segregadas, marcada por las conductas marginales de los jóvenes populares (Dubet, 1987a, 1987b), entre ellas, el «inactivismo político» (Sabatini, Cáceres y Cerda, 2001; Tironi, 2003).

El Estallido Social de Octubre profundizó la crítica en torno a la despolitización de los jóvenes populares, lo cual ya había sido advertido por la movilización pingüina en el año 2006. Durante este, se observó una amplia participación de jóvenes de barrios de bajo estatus, tanto en el centro de Santiago y de sus comunas, como al interior de sus propias poblaciones y villas. Dentro de su repertorio de acción, se observaron formas de protesta disruptivas y violentas, como barricadas y reiterados ataques a comisarías, hechos rápidamente criminalizados por el gobierno y la opinión pública. Paralelamente, en estos territorios populares, se organizaron cabildos y asambleas territoriales con un alto 
protagonismo juvenil. Así, se comprende, por ejemplo, el aumento de la votación de jóvenes en el plebiscito de octubre de 2020, en comunas como La Pintana y Puente Alto (Engel et al., 2020). No obstante, salvo excepciones, en este sufragio se mantuvo la tendencia a una menor participación juvenil en los distritos populares (Bargsted y Delgado, 2021).

¿Cómo se ha interpretado, desde la sociología, la participación de jóvenes populares en rebeliones en la ciudad contemporánea? En un libro muy influyente dentro de los estudios urbanos, Löic Wacquant (2007) comienza su descripción de las transformaciones en la pobreza urbana a partir de las distintas revueltas ocurridas a finales de los años ochenta en Francia, Inglaterra y Estados Unidos ${ }^{5}$. Desde su perspectiva, los diferentes episodios de violencia colectiva protagonizados por jóvenes de barrios pauperizados y altamente segregados constituían una «reacción» a la violencia estructural, la cual tiene tres componentes principales: desempleo masivo, relegación a los barrios desposeídos y estigmatización territorial. A estas transformaciones se sumaba la desarticulación política de la clase trabajadora, expresada en la decadencia del movimiento obrero, de los partidos tradicionales de izquierda y del movimiento por los derechos civiles, todo lo cual impactaba negativamente en las posibilidades de actuación política de los jóvenes de la marginalidad avanzada. Estos, simplemente, carecían de instrumentos institucionales para formular reivindicaciones colectivas sobre la base de una identidad común en el espacio político. Así, para Wacquant (2007), el único medio disponible para la expresión colectiva juvenil era la protesta infrapolítica, es decir, las disrupciones populares del orden público, por medio de saqueos y la destrucción de propiedad pública y privada.

En el mismo sentido de desolación y desesperanza política, a partir de una investigación realizada en las banlieues francesas, François Dubet señalaba, a fines de 1980, que la acción de los jóvenes populares no tendría ningún sentido afirmativo:

En el agujero y vacio dejados por la destrucción de las antiguas formas de conciencia de clase y por la ausencia de nuevos movimientos sociales, los

\footnotetext{
${ }^{5}$ Es de notar que esa introducción sobre las revueltas urbanas de las clases bajas se basa en una conferencia bastante anterior, dada por Wacquant en 1993 en el Congreso anual de la Associação Nacional de Pós-Graduação e Pesquisa em Ciências Sociais (ANPOCS) de Brasil.
} 
actores no definen ningún adversario social y ningún conflicto específico [...] La violencia y el sentimiento de vivir en una jungla reemplazan al conflicto y el actor de las clases peligrosas se define como «enrabiado» (Dubet, 1987a: 24).

Pero ¿son suficientes, hoy, las nociones de rabia o reacción para interpretar la participación de los jóvenes pobres en las revueltas urbanas? ¿Puede ser descrito el mundo popular contemporáneo como un «paisaje lunar» (Wacquant, 2007) dominado por conductas marginales y falta de sentido comunitario? Contrario con esa visión nostálgica de las movilizaciones de las clases trabajadoras, vía huelgas, protestas y sindicatos, parámetro desde el cual los jóvenes actuales son descritos como «enrabiados», «reactivos» o «inactivos», en este artículo se sostiene, primero, que el universo popular es bastante más heterogéneo que el usualmente descrito por los estudios urbanos (Small, 2007; Salcedo y Rasse, 2012); y, segundo, que su comportamiento político, lejos de ser una simple «reacción» a la violencia estructural del mercado y el Estado, es resultado de la forma en que interpretan y se relacionan tanto con su realidad cotidiana como con distintas experiencias fuera de su barrio.

Para demostrar este argumento, presentaremos resultados de dos investigaciones: una, aún en curso, sobre participación política en poblaciones altamente estigmatizadas del Gran Santiago ${ }^{6}$; y otra, ya finalizada, sobre motivaciones, justificaciones y valoraciones de las acciones disruptivas en barrios populares durante el Estallido Social ${ }^{7}$. El trabajo de campo, en ambos proyectos, comenzó en diciembre de $2019^{8}$, pero en marzo de 2020, por efecto de la pandemia, continuó en formato online. En ese trascurso, de un total de treinta relatos de vida (Bertaux, 2005), hechos a mujeres y hombres residentes de dos villas localizadas en sectores con altos índices de pobreza de las comunas de Puente Alto y Maipú, nueve entrevistas han sido realizadas a jóvenes,

${ }^{6}$ Proyecto Fondecyt de Iniciación ( $\left.\mathrm{N}^{\mathrm{o}} 11190211\right)$, «Del protagonismo a la abstención? Estudio sobre participación política en barrios populares del Gran Santiago». Investigación aún en curso que explora las formas de acción política institucional y contenciosa entre residentes de barrios con altos índices de pobreza, segregación y narcomenudeo. Investigador responsable: Nicolás Angelcos.

${ }^{7}$ Proyecto FONDAP N¹5130009, «Análisis etnográfico de las movilizaciones sociales en barrios periféricos del Gran Santiago». Investigador responsable: Nicolás Angelcos. Además, forman parte del equipo: Andrea Roca, Emilia Cuadros, Valentina Álvarez, María Luisa Méndez y Alejandra Rasse.

${ }^{8}$ Si bien la fase de campo del proyecto arranca post Estallido Social, estos estudios responden a una agenda de investigación de larga data sobre la reemergencia de la política popular (Angelcos y Pérez, 2017). 
mayormente hombres, entre 21 y 31 años. A diferencia de los estudios de Dubet, Wacquant o Bourgois, donde los protagonistas son en su mayoría jóvenes cuyas trayectorias están marcadas por el fracaso escolar, la violencia delictual y el consumo de droga, los interlocutores de este trabajo son jóvenes con distintas formas de incorporación a la educación superior (ver Cuadro 1).

El criterio metodológico de recopilar y analizar trayectorias de jóvenes de barrios de bajos ingresos que acceden a la educación superior, responde a dos razones. Primero, al interés de dar cuenta del heterogéneo mundo popular actual chileno, donde hay jóvenes que no solo consiguen o intentan niveles educativos inéditos en sus familias, y con ellos nuevas expectativas y sentidos de vida, sino que, además, sus referencias exceden los confines del barrio al estar altamente conectados a redes sociales y de información. Y segundo, por la función que desempeñarían los individuos de clases bajas, pero con niveles de estudios superiores en las revueltas urbanas contemporáneas (Bayat, 2015). Como veremos, estas diferencias son importantes para comprender sus relatos de las movilizaciones iniciadas en octubre de 2019. Por último, quisimos diversificar el universo de experiencias juveniles populares, incluyendo a mujeres y hombres con experiencias de participación. De esta forma, entre los entrevistados, algunos participan o participaron en organizaciones culturales, políticas y/o religiosas, y otros han optado principalmente por un proceso de movilidad social individual. 


\section{CUADRO 1. DESCRIPCIÓN JÓVENES ENTREVISTADOS}

\begin{tabular}{|c|c|c|}
\hline Nombre & Edad & Descripción \\
\hline Javiera & $\begin{array}{l}23 \\
\text { años }\end{array}$ & $\begin{array}{l}\text { Estudiante Universidad alta selectividad. Trabaja como } \\
\text { empaquetadora en supermercado en comuna periférica. }\end{array}$ \\
\hline Claudia & $\begin{array}{l}21 \\
\text { años }\end{array}$ & $\begin{array}{l}\text { Estudiante Universidad alta selectividad. Ayuda en almacén de } \\
\text { sus padres. }\end{array}$ \\
\hline Mario & $\begin{array}{l}20 \\
\text { años }\end{array}$ & $\begin{array}{l}\text { Estudiante Universidad alta selectividad. Ayuda en almacén de } \\
\text { sus padres. }\end{array}$ \\
\hline Roberto & $\begin{array}{l}23 \\
\text { años }\end{array}$ & $\begin{array}{l}\text { Estudiante postgrado Universidad alta selectividad. Ex } \\
\text { integrante colectivo hip hop. }\end{array}$ \\
\hline Eduardo & $\begin{array}{l}23 \\
\text { años }\end{array}$ & $\begin{array}{l}\text { Estudiante Universidad alta selectividad. Activo feligrés en } \\
\text { culto evangélico. }\end{array}$ \\
\hline Ariel & $\begin{array}{l}31 \\
\text { años }\end{array}$ & $\begin{array}{l}\text { Estudiante Instituto Técnico Profesional. Militante partido de } \\
\text { izquierda extraparlamentario. Director de ONG en la periferia } \\
\text { de Santiago. }\end{array}$ \\
\hline Ramón & $\begin{array}{l}22 \\
\text { años }\end{array}$ & $\begin{array}{l}\text { Exestudiante Instituto Técnico Profesional. Militante partido de } \\
\text { izquierda extraparlamentario. }\end{array}$ \\
\hline Álvaro & $\begin{array}{l}23 \\
\text { años }\end{array}$ & $\begin{array}{l}\text { Estudiante Instituto Técnico Profesional. Músico rock y } \\
\text { productor audiovisual. }\end{array}$ \\
\hline Salvador & $\begin{array}{l}26 \\
\text { años }\end{array}$ & $\begin{array}{l}\text { Licenciado en Historia. Universidad alta selectividad. Trabaja } \\
\text { en colegio periférico. }\end{array}$ \\
\hline
\end{tabular}

Fuente: Elaboración propia.

El artículo se estructura de la siguiente forma: en la primera parte, reconstruiremos brevemente el campo de estudios nacionales sobre la participación política juvenil popular; en la segunda parte, presentaremos los principales hallazgos, distinguiendo tres tipos de trayectorias juveniles y su posicionamiento respecto al Estallido Social; finalmente, realizaremos algunas reflexiones y preguntas para continuar con la investigación aún en curso. 


\section{JUVENTUD POPULAR Y PARTICIPACIÓN POLÍTICA}

En Chile, la preocupación sociológica por el comportamiento político de los jóvenes populares surge en el contexto de la crisis económica que afectó al país durante la década de los ochenta y las jornadas de protesta que se inician en 1983. En este escenario de movilización, adquirieron visibilidad jóvenes desempleados y sin mayor adhesión al espacio de la escuela (Aguilera y Muñoz, 2015). En ese campo, fue pionero el trabajo de Eduardo Valenzuela (1984), quien, desde el concepto de anomia (en su vertiente mertoniana), se centra en las distintas formas de desviación que caracterizan el comportamiento juvenil, en especial, su actuación en episodios de violencia colectiva. En la misma línea, Dubet (1987b) focaliza sus análisis en las conductas marginales, esta vez, de jóvenes pobres chilenos, para concluir que las protestas contra la dictadura respondían a una «lógica desviacional expresiva» ubicada en el límite entre delincuencia y política.

La recuperación de la democracia, en 1990, implicó una reorientación de los enfoques teóricos con que se observaba a la juventud popular: por una parte, en continuidad con el período anterior, se percibía a los jóvenes como anómicos, que debían ser integrados al proceso de modernización que experimentaba el país; y, por otra, se les consideraba en riesgo psicosocial, lo cual refería a los efectos negativos del entorno social sobre el desarrollo de su personalidad (Goicovic, 2000). Ambos enfoques dejaban de reconocer a los jóvenes en general y a los de barrios populares en especial como actores políticos (Aguilera y Muñoz, 2015).

A comienzos de los años 2000, en una óptica diferente, varios estudios adoptaron las nociones de «subculturas juveniles» y «tribus urbanas», resaltando el impacto de las afinidades y los afectos en estas formas de actuación colectiva, descritas como una micropolítica donde se reproducen componentes identitarios sobre la base de parámetros éticos y estéticos (Correa y Sandoval, 2009; Valenzuela, 2007; Zarzuri y Ganter, 2002). Así, por ejemplo, el «hip hop social» fue leído en las poblaciones como resistencia activa, desde la cultura, contra la invisibilización y estigmatización socioterritorial sufrida y la búsqueda de una voz propia por parte de los sujetos excluidos (Bade, 2004; Muñoz, 2002).

Tanto en la producción contracultural como en la explosiva emergencia de colectivos y organizaciones de base a lo largo del país, se empieza a reconocer un sentido reivindicativo de lo «poblacional». Algunos identifican entre sus 
participantes un rechazo a la noción de ciudadanía, entendida como heterodesignación que representa un posicionamiento acrítico y adultocéntrico que bloquea la participación real de los sectores excluidos del sistema político (Gamboa, 2005). En cambio, otros, como Salazar (2012), destacan la conformación de una «nueva ciudadanía popular», que hace del espacio local el lugar de cambio social y que se expresa en una dispersión de «moléculas de soberanía popular», que irían desde las escuelas de educación popular, hip hop social, talleres de malabarismo, a las asambleas territoriales, dando forma a una «cultura sociopopular autogestionaria»y de «proyección constituyente», que, si bien novedosa, sería heredera de las experiencias de acción directa de los sectores populares a lo largo de la historia nacional.

Para entender este incremento de la organización juvenil poblacional, es importante identificar las articulaciones entre colectivos y el mundo universitario. La integración al sistema de educación superior de jóvenes de clases bajas, a raíz de reformas educacionales, ha afianzado dicha relación: tal como ha señalado Salazar (2012), en un gesto de reflexividad activa y compromiso social, jóvenes populares, hoy estudiantes universitarios, investigan desde distintas disciplinas los colectivos políticos y culturales de sus barrios de pertenencia, contribuyendo en la construcción de una memoria local sobre las experiencias de poder popular y la conformación de proyectos políticos antagónicos y contraculturales en las periferias de la ciudad.

Como podemos observar, dentro de la sociología chilena de la juventud, se ha identificado un panorama de participación política bastante más heterogéneo que la «jungla» descrita por Dubet (1987a) en los barrios populares franceses, el «paisaje lunar» al que hace referencia Wacquant (2007), en alusión al «hipergueto» norteamericano, o el «desierto de movilización popular» que observan Sabatini y Wormald (2004) en las poblaciones chilenas. Desde los años 2000 , estos estudios logran identificar y debatir sobre formas novedosas de organización que constituyen importantes fuentes de identidad para los jóvenes populares, dotándolos de un lenguaje con el cual expresarse políticamente.

A partir de estos antecedentes, a continuación, reconstruiremos los relatos del Estallido Social de Octubre y el proceso constitucional desde la perspectiva de jóvenes que viven en poblaciones y villas altamente estigmatizadas de la periferia del Gran Santiago. A diferencia de reportajes periodísticos que han enfatizado el protagonismo en saqueos y escaramuzas con la policía en los meses de protestas, de jóvenes afectados por experiencias de pobreza, violencia y 
abandono ${ }^{9}$, en lo que sigue ofrecemos un cuadro donde los protagonistas son jóvenes también de barrios de bajo estatus, pero que exhiben trayectorias de movilidad social, de participación artística contracultural, en agrupaciones religiosas, así como en militancias de izquierda. A partir de las múltiples experiencias generosamente compartidas por los jóvenes que accedieron a participar de este estudio, a continuación serán discutidos los sentidos, expectativas y anhelos que despuntaron en el Estallido Social de Octubre.

\section{JÓVENES DECENTES: MOVILIDAD, EDUCACIÓN SUPERIOR Y PARTICIPACIÓN POLÍTICA INSTITUCIONAL ${ }^{10}$}

Entre los jóvenes interlocutores, se encuentran aquellos que han vivido un proceso de movilidad social ascendente, que se expresa tanto en la posibilidad de continuar sus estudios en universidades altamente selectivas, pero, además, por el cambio de residencia dentro de la misma población. Matizando el deseo de abandonar la población que supuestamente atravesaría a los pobres urbanos en tiempos de la «nueva marginalidad» (Wacquant, 2007), las familias de estos jóvenes han optado por continuar viviendo en las cercanías de los conjuntos de vivienda social, pero en casas a las cuales han accedido ya no mediante subsidios estatales, sino por medio de créditos bancarios.

Para estos estudiantes, la cultura de la calle, la violencia, el consumo de drogas y el narcotráfico son una realidad cotidiana y será desde la inseguridad y el conflicto en el espacio común, desde donde comprenderán parte importante del mundo social del barrio:

Estaban peleando unos vecinos y salieron con estos sables al medio de la calle. Los vecinos, asustados, llamaron cinco, seis veces [a Carabineros] y no aparecieron, no apareció nadie y, a la final, los mismos vecinos salieron a

${ }^{9}$ Ver, por ejemplo, «Saqueos, violencia y capuchas: el despertar de Chile en los ojos de los adolescentes de Santiago Sur», El Desconcierto, 11/11/2019. Disponible en: https://www.eldesconcierto.cl/nacional/2019/11/29/saqueos-violencia-y-capuchasel-despertar-de-chile-en-los-ojos-de-los-adolescentes-de-santiago-sur.html

${ }^{10}$ Una parte de este análisis fue publicado originalmente en el libro Saltar el torniquete: reflexiones desde las juventudes de octubre, editado por Sol Alé, Klaudio Duarte y Daniel Miranda (FCE, 2021). 
dispersar, de ahí salió un traficante y disparó al cielo para que se calmaran. (Javiera, 23 años, universidad alta selectividad).

Javiera, quien narra esta escena, vive en uno de los sectores más conflictivos de su población, blocks de vivienda social ubicados justo frente a las villas en que viven Mario y Claudia, compañeros de su misma universidad, pero con un mejor pasar económico, debido a los almacenes de abarrotes que tienen sus padres. Para estos tres jóvenes, más allá de los recursos disponibles, los resultados positivos de su trayectoria educacional son el resultado de estrategias familiares orientadas al logro académico, donde la madre representa una figura central, tanto como «mamá helicóptero», aquella pendiente de monitorear y aprovechar cada oportunidad para sus hijos (becas, cursos gratuitos), como «mamá mano dura», aquella que obliga a mantenerse lejos de la calle. En la autocomprensión de estos jóvenes, es el control parental lo que explica la diferencia entre ellos y sus compañeros de colegio y amigos de infancia del barrio que se «desviaron» o «perdieron», ya sea por el consumo de drogas o por el embarazo adolescente y consiguiente abandono de estudios.

Los relatos de estos jóvenes parecieran adherir a la «cultura de la decencia» descrita por Martínez y Palacios (1996). Para estos autores, al interior de la pobreza, hay quienes persiguen un estricto código moral que resalta los valores de la honradez, la honra (especialmente el rechazo a la promiscuidad sexual en jóvenes mujeres), la temperancia (el rechazo al consumo excesivo de alcohol o drogas) y la fe o causa (religiosa o política). Si bien este código se piensa, principalmente, desde una posición masculina, adulta y de clase trabajadora, estos jóvenes lo utilizan para significar sus trayectorias universitarias en oposición a sus vecinos, para lo cual establecen marcadas fronteras morales (Lamont y Bail, 2005). De esta forma, se distinguen de aquellos que consideran menos valiosos, no tanto por su bajo capital económico, como por su comportamiento disruptivo («puros cabros brígidos», «que no dejan vivir»), por su reticencia al trabajo honrado, así como por su escaso interés en lo político y lo comunitario.

Estas fronteras implicaban un control muy estricto de su comportamiento, especialmente respecto a su circulación en el barrio. Este mismo control operaba en el momento del Estallido Social, limitando sus formas de participación en la protesta. Ninguno de ellos participó en actos de violencia y, en el caso de asistir a manifestaciones, sus familias les permitían ir a sectores cercanos o con adultos confiables que se hicieran cargo de su cuidado. Su compromiso con la movilización social se caracterizaba más bien por su participación en caceroleos 
$\mathrm{y}$, en algunos casos, con formas de asociatividad surgidas a propósito del estallido, tales como cabildos y asambleas territoriales.

La experiencia de octubre, además, les permitió reforzar las fronteras morales establecidas entre ellos y los «otros». Pese a que reconocían el involucramiento de algunos de sus vecinos en los caceroleos, los describen como personas apáticas, desinteresadas, pasivas, dispuestas al intercambio clientelar con la política. De esta forma, tendían a reproducir los estereotipos con que los estudios urbanos y la ciencia política han descrito el comportamiento político de los individuos de sectores populares, especialmente de los más jóvenes. Al contrario, ellos, con un mayor capital cultural, tendrían un interés genuino en el proceso de transformación social y política que experimenta el país.

La mayoría de los que somos más jóvenes estábamos informados del descontento, de por qué eran las demandas (...). La otra gente salía como por salir a apoyar (...), pero aquí la gente es bien desinformada la mayoría, la mayoría de acá no vota, les da lo mismo. (Javiera, 23 años, universidad alta selectividad).

Para estos jóvenes, la política institucional es un camino legítimo, pese a que comparten muchas de las críticas que circulan en la opinión pública hacia los partidos políticos y sus principales representantes. Están interesados en el proceso constitucional en curso, son críticos del acuerdo alcanzado entre el gobierno y la oposición, pero no lo rechazan. Apuestan por la aparición de figuras políticas jóvenes, de nuevos partidos, tienen más afinidad con la izquierda y expresan esperanza respecto a los cambios que puedan surgir de esta crisis.

Aquí la gente cae en el típico «no han tocado las AFP, no han tocado las Isapres, ¿y ahora van a cambiar la Constitución?». Yo creo que es importante que entiendan que la Constitución es el puntapié inicial para todo. (Mario, 20 años, universidad alta selectividad).

La principal controversia que enfrentan estos jóvenes es a propósito de los saqueos durante la primera semana del Estallido Social, sobre todo considerando que, tal como señalamos, en dos casos, sus familias tenían almacenes y todos los supermercados de su entorno cercano fueron desvalijados. Ninguno de estos jóvenes rechaza los saqueos a grandes tiendas y tienden a justificarlos tanto por la pobreza del sector como por el comportamiento abusivo de los empresarios. Sin embargo, lo que sí les molesta de estos eventos fue un conjunto de prácticas desplegadas por los saqueadores que confirman sus 
prejuicios negativos hacia sus vecinos («gente que está acostumbrada a la vida fácil»). Por ejemplo, critican prácticas de acaparamiento de algunos vecinos que, después de haber saqueado en reiteradas ocasiones, no quisieron compartir parte de los productos apropiados, o prácticas de especulación cuando saqueadores vendían los productos en la feria a un precio mucho más alto del que tenían originalmente. En este sentido, existía una cierta expectativa de redistribución asociada a la práctica del saqueo que fue defraudada y que confirmaba el carácter individualista y desinteresado de sus vecinos en relación con la comunidad.

En este sentido, estos jóvenes populares que cursan carreras universitarias son críticos de lo que ocurre en el país y en sus barrios, inclusive de sus propios vecinos. Si bien su participación en las protestas estuvo obstaculizada por sus entornos familiares, los cuales buscaban protegerlos, así como durante sus vidas los protegieron de los peligros del sector, fueron muy activos por redes sociales, compartiendo noticias que no eran divulgadas por los medios de comunicación hegemónicos y asumiendo un rol activo en informar y concientizar a sus vecinos y familiares sobre la importancia de las demandas sociales para mejorar las condiciones de vida de la población.

\section{ENTRE LA DECENCIA Y LA CONTRACULTURA: RELIGIÓN, RAPY PARTICIPACIÓN POLÍTICA}

Entre los jóvenes que entrevistamos, no todos tienen trayectorias que los diferencien tan claramente de sus vecinos. Su adolescencia en el colegio del barrio era un espacio de socialización importante, en el cual desarrollaban prácticas como el consumo de drogas y alcohol que, hoy, en retrospectiva, creen que los podrían haber desviado respecto a sus expectativas de acceso a la educación superior. En este sentido, alejarse de los «malos pasos» es un hito que marca sus relatos de vida, lo cual, en algunos casos, es apoyado y promovido por sus familias, pero, en otros, es el resultado de un importante proceso de reflexión individual. Los caminos para «reencauzar» sus trayectorias son heterogéneos. Para Eduardo, estudiante universitario, la participación familiar en la iglesia evangélica operó constantemente como un contrapeso respecto a la «cultura de la calle» (Bourgois, 1995).

En mi adolescencia, igual sentía que, al hablar con mis compañeros, tenía como otras miras de la vida y otras formas de comportamiento que chocaban igual con lo que a mí se me enseñaba en la iglesia, entonces, siempre tenía como este 
conflicto. Participaba con mis amigos, sí, pero siempre como con reserva. (Eduardo, 23 años, universidad alta selectividad).

El participar de la iglesia evangélica, sumado al apoyo constante de su familia, operó como un soporte valórico clave para orientar su trayectoria hacia la educación superior. Sin embargo, este refugio en la iglesia también lo ha distanciado de la política. Su relato del estallido está marcado por el rechazo hacia los saqueos y, en general, de la violencia, los cuales, a su parecer, fueron protagonizados por «delincuentes con pistolas y las medias camionetas». Desde su perspectiva, los saqueos son una expresión más de la «cultura de la calle», respecto a la cual él y su familia han buscado constantemente distanciarse. Esto no implica el desconocer la desigualdad económica que, para él, está en la base de las protestas de octubre. Al contrario, su experiencia en la educación superior, especialmente la diferencia de capital cultural con sus compañeros y los largos traslados desde su barrio al centro de Santiago, además de su experiencia familiar en los centros de salud, marcada por los problemas que han afectado a su hermano, son una prueba irrefutable de la «brecha» que separa su realidad y la de sus vecinos respecto a los más privilegiados. Sin embargo, como él reconoce, esto lo había naturalizado en la medida que la trayectoria de su padre y su propia trayectoria confirman que la movilidad social es posible, en la medida que uno se «esfuerce» y decida alejarse de las «malas influencias».

En relación con el cambio constitucional, se muestra pesimista, primero, porque ve difícil que, entre todos, se pueda alcanzar un acuerdo y, segundo, porque considera que él y sus vecinos no tienen el capital cultural suficiente para participar del proceso. Esta percepción lo lleva, incluso, a declarar que no tiene el conocimiento suficiente para votar en el plebiscito. Esta actitud de retraimiento respecto al proceso constitucional es alimentada también por la iglesia en que participa, la cual restringe explícitamente su acción a los problemas espirituales, sin definir ninguna postura en relación con los asuntos mundanos, entre ellos, la política.

A diferencia de Eduardo, Álvaro y Roberto han optado por expresar su voz a través de la música. Tal como describen los estudios urbanos (Caldeira, 2010), la historiografía contemporánea (Lagos, 2017; Poch, 2009; Redolés y Pedreros, 2011; Reyes, 2011) y los estudios de juventud (Moraga y Solozarno, 2005; Tijoux, Facuse y Urrutia, 2012), el rock, el rap, el hip hop y, actualmente, el trap representan formas expresivas a través de las cuales los jóvenes construyen un importante sentido de dignidad y se apropian afirmativamente de 
las condiciones de pobreza y violencia que afectan cotidianamente a sus barrios. Esto, sin embargo, no desemboca necesariamente en un compromiso con el proceso político. De hecho, Álvaro, pese a que se ha dedicado a retratar la desigualdad de su población a través del cine y el rock, combatiendo el «estigma territorial» (Wacquant, Slater y Borges Pereira, 2014) que, a su juicio, refuerza la televisión cuando los trata de «gueto», no presenta mayor interés por el Estallido Social ni por el cambio constitucional, salvo que se vincule directamente con el cambio en las condiciones de vida en la población.

No obstante, la música, en otros casos, sí representa un espacio significativo de socialización política. Tal es el caso de Roberto, joven mapuche, quien conoce el rap en su adolescencia, motivado, al igual que Álvaro, por alejarse de otros compañeros de su colegio que lo estaban llevando por «malos pasos». A diferencia de la participación en la iglesia evangélica ya descrita, entrar en un colectivo de rap no lo desvinculaba de los asuntos mundanos, sino, al contrario, le entregaba un lenguaje político que le permitía identificar la violencia estructural (Wacquant, 2007) que explica las dificultades que él y sus vecinos enfrentan en la población. En referencia a los líderes del colectivo de rap, mayores que él, señala:

Estos chicos tenían esta postura de que, en el fondo, había que hacer música, pero que tuviera un mensaje, que proyectara también un sentido de resistencia frente a lo que nos imponen. Ahí fue la primera vez que escuché la palabra neoliberalismo y también resistencia y otras cosas más, pero justamente, como que estos mensajes fueron cuajando de a poco dentro de mí. (Roberto, 23 años, estudiante postgrado, universidad alta selectividad).

Para Roberto, el colectivo de rap representó un importante espacio de socialización que, como ya señalamos, le permitió incorporar un lenguaje político para interpretar su realidad. Asimismo, lo vinculó con otras organizaciones y dirigencias al interior de la población que generaban actividades solidarias para enfrentar, por ejemplo, los costos de operación de un vecino. En relación con el Estado, su colectivo critica duramente la demolición de bloques de departamentos ejecutada como parte de un plan de renovación urbana. En un video realizado por uno de los líderes de la organización, se describe el plan como «Terrorismo de Estado». Al respecto de las malas condiciones de vivienda, la posición frente al plan fue progresivamente dividiendo a los vecinos entre quienes querían, a través de un subsidio del Estado, irse definitivamente de la población y quienes querían quedarse, porque, pese a las dificultades cotidianas que enfrentan, valoran el vivir ahí. Este último discurso, el de la pertenencia, le 
hacía sentido a Roberto y le permitía enfrentar el estigma territorial que pesa sobre la población.

Ha sido toda una vida acá en la población y, en el fondo, que ahora nos vengan a estigmatizar de que somos como un nido de delincuentes, de que acá hay mucho narcotráfico. Es como, sí, es verdad, es una realidad objetiva. Tú podí ver gente traficando en la esquina, consumiendo pasta y todo, pero, en el fondo, el barrio es mucho más que eso. Hay, por ejemplo, los colegios, los niños. Acá hemos hecho toda la vida, entonces, y acá queremos seguir haciéndola. Y eso decían las vecinas y, en parte, nosotros también le encontramos razón y sentido. (Roberto, 23 años, estudiante postgrado, universidad alta selectividad).

Además de la socialización política que implicaba su participación en el colectivo, el rap también despertó su interés por seguir estudios en la universidad, a pesar del intento fallido de su hermano por ingresar a la educación superior. Al igual que en la mayoría de nuestras entrevistas, la universidad significó un «shock», marcado por las desigualdades de capital económico y capital cultural con sus compañeros, además, por distintas situaciones de discriminación sufridas por su hermano y otros amigos por parte de profesores y estudiantes. Tal como en el caso anterior, los largos viajes al centro desde su población - los cuales compara con la vida laboral de su padre - fueron nutriendo su «rabia». Sin embargo, a diferencia de lo señalado por Dubet (1987a), esto no implicaba una confusión respecto al carácter clasista de la desigualdad, ni tampoco una simple «reacción» (Wacquant, 2007) en episodios de violencia:

Yo entré a la universidad el 2015, entonces igual ir pasando todo eso, ir viendo todo eso y también ya haciéndome la idea de, o sea, no sé, de que, en el fondo, nuestra forma de vida beneficiaba a un grupo que se beneficia directamente de la precariedad de las personas. Fui juntando mucha rabia, mucha rabia, mucha, mucha, mucha rabia. Eso mismo me motivaba para participar de las protestas en la universidad, para seguir estudiando también, pero fui alimentando mucha rabia de cada viaje en el metro, de cada viaje en la micro, de ver a la gente tan maltratada, en el fondo, por el sistema. (Roberto, 23 años, estudiante postgrado, universidad alta selectividad).

En este fragmento, la rabia producto de la experiencia denigrante de los traslados en un sistema de transporte precario, pero, además, por la constatación de las desigualdades sociales manifiestas al circular por la ciudad y ver otros 
barrios de alto estatus ${ }^{11}$. Además, Roberto asocia la rabia tanto a la protesta, en algunos casos, violenta, como a la motivación para seguir estudiando. Es desde este lugar que relata el estallido como un «desahogo completo». Sobre los saqueos en su barrio, sintió decepción. Para él, a diferencia de la violencia en las barricadas, los saqueos son un fenómeno delictual en el que participaron bandas de narcotraficantes $\mathrm{y}$, en algunos casos — reconoce con dolor-, «cabros conocidos». Respecto al proceso constitucional, probablemente por su socialización política en el colectivo de rap, aspiraba a un «cambio radical», el cual habría sido contenido por el acuerdo firmado entre el gobierno y parte de la oposición. Pese a esto, y a diferencia del relato anterior, se siente esperanzado en que el cambio en la Constitución puede representar un avance en «mayor justicia social», por lo que se muestra muy interesado de participar del plebiscito.

Finalmente, pese a que en el colectivo de rap se socializó políticamente y se identifica con la izquierda, es bastante reticente a la participación en partidos políticos. Su salida del colectivo de rap es resultado del intento, por parte de algunos líderes, de articular este grupo con un partido político de la izquierda extraparlamentaria. Asimismo, en su formación de pregrado participó activamente en un preuniversitario popular en La Pintana, pero no quiso aceptar la invitación de militar en la «Jota», porque «no había libertad de pensamiento». Dentro de las opciones partidarias, reconoce que, inicialmente, se sentía atraído por el Frente Amplio, pero ya no: «Tratan de estar con la gente, con el pueblo, con la ciudadanía, pero son puros hijitos de papá». Esta reticencia con la política partidaria es coherente con la lógica de los colectivos contraculturales: estos ofrecieron una alternativa al paradigma de la militancia partidaria de izquierda, abriendo espacio a una militancia social que, en tanto proyecto de autorrepresentación y de repolitización de la vida cotidiana (Ganter y Zarzuri,

${ }^{11}$ Experiencias parecidas han sido reportadas por otros estudios (Badilla, 2020), donde la constatación de las carencias de su espacio vivido motiva a jóvenes a informarse, aprender y denunciar las políticas urbanas que dieron forma a la ciudad segregada neoliberal, pero, además, los llevaron a querer conocer las historias de organización y resistencia de sus barrios de pertenencia, territorios que no forman parte de las poblaciones «emblemáticas». 
2020), concilia distintas facetas de la experiencia popular, como veremos más adelante $^{12}$.

\section{JÓVENES MILITANTES: COMPROMISO POLÍTICO, ORGANIZACIÓN BARRIAL Y TRANSFORMACIÓN SOCIAL}

Como hemos visto en secciones anteriores, las trayectorias de los jóvenes entrevistados constituyen distintas formas de responder a la «cultura de calle»y la violencia cotidiana que describen los estudios urbanos contemporáneos. El acceso a la educación superior, especialmente en el caso de las universidades selectivas, representa un importante logro para estos jóvenes y sus familias, sin embargo, no todas sus estrategias son individuales. Como se problematiza en los últimos dos relatos, la participación en organizaciones religiosas y artísticas también les permite acceder a otros códigos culturales que nutren su camino a la universidad. Estas distintas trayectorias, como se ha mostrado, afectan la manera en que estos jóvenes interpretan el Estallido Social y se vinculan con el actual proceso político a nivel nacional.

A continuación, se profundizará en otras trayectorias que, sin necesariamente abandonar las expectativas asociadas a la educación superior, optan directamente por la organización política. En algunos casos, este interés proviene de un capital político heredado de generaciones anteriores, pero no siempre es así. Lo característico de estos relatos son los distintos compromisos políticos que fueron adquiriendo desde el colegio y que, dependiendo de la trayectoria, se refuerzan en la universidad. Al momento de ser entrevistados, todos buscaban la forma de incidir políticamente sobre su propio territorio, ya sea a través de la participación en barricadas, ollas comunes o asambleas territoriales. Lo interesante de esta participación es que, a diferencia de lo

${ }^{12}$ En el caso del hip hop brasileño, Caldeira (2010), junto con reconocer la relevancia de esas prácticas artísticas para la denuncia de la violencia y la desigualdad social que afecta a los barrios marginalizados, destaca dos importantes límites que podrían ser analizados, en un futuro, a propósito del hip hop o el trap nacional. A diferencia de los movimientos sociales urbanos, cuya lucha buscaba el reconocimiento político de derechos sociales y la inclusión ciudadana, para los raperos, se trata de un proyecto político que exacerba las diferencias entre centro y periferia, reivindicando una autonomía radical que se traduce, paradojalmente, en un refuerzo de la lógica segregacionista. Asimismo, destaca su marcado carácter masculino, al interior del cual, las mujeres no son reconocidas como sujetos más allá de su condición de madres. 
planteado a propósito de los colectivos populares (Salazar, 2012; Gamboa, 2005), no es incompatible con la participación política institucional. De hecho, los interlocutores han militado o militan en organizaciones o partidos políticos de izquierda no tradicionales, llegando inclusive a participar como candidato en elecciones municipales. Es importante destacar esto, pues se piensa que el giro de las organizaciones juveniles hacia la política institucional es propio de la clase media universitaria, sin considerar otras organizaciones que, aun cuando tengan menos visibilidad, han optado también por una estrategia institucional ${ }^{13}$.

El relato que estos jóvenes despliegan respecto a su barrio no se estructura en torno a la violencia cotidiana y el narcotráfico, sino más bien a identificar las causas estructurales que explican el fenómeno. Si bien son conscientes de las diferencias de trayectorias entre las familias, se resisten a establecer fronteras morales rígidas con sus vecinos. Este es el caso de Ariel, activista social y militante político ${ }^{14}$. Al momento de describir el mundo poblacional, en vez de segmentar, reconoce la diversidad como un elemento clave y estratégico de la experiencia popular en tanto clase social.

Es un espectro súper diverso y es súper difícil navegar ahí porque te pueden tirar pistolas, cualquier persona te puede tirar mierda porque estai en todos lados, pero igual nosotros y nosotras entendemos que esa es la diversidad cachai, de nuestra clase, me entendi, que somos profundamente diversos. (Ariel, 31 años, activista social y militante político).

Es así como promueve un discurso político que, reconociendo explícitamente las diferencias culturales al interior de la población, no solo desactiva la oposición entre militancia política y «cultura de la calle» (Bourgois, 1995), al reconocer positivamente a sus «compas» con más experiencia callejera y en barras de fútbol, sino que, además, ha logrado articular un discurso que impugna la definición histórica que ha dado la izquierda a la noción de «pueblo»: «Estábamos cansados de la idealización del sujeto popular de izquierda, como

${ }^{13}$ Respecto a la relación entre organizaciones populares contemporáneas y partidos políticos, se sugiere revisar dos trabajos desarrollados por uno de los autores sobre el Partido Igualdad (Angelcos, 2016; Angelcos, Jordana y Sandoval, 2019).

${ }^{14}$ La trayectoria de Ariel es difícil de encasillar. Tiene una historia de militancia política en colectivos de izquierda sin estrategia institucional y actualmente en un partido que sí la tiene. Sin embargo, es difícil describirlo como un militante de partido en un sentido convencional. Al mismo tiempo, participa de muchas iniciativas de ayuda a la comunidad que no son necesariamente políticas. 
que si no decís bien una palabra, eres un weón flaite. Para nosotros, ser flaite es ser popular también po».

Para estos jóvenes, el Estallido Social fue un evento esperado, aún más, anhelado, sobre la base de su lectura crítica de la realidad chilena y el trabajo militante realizado («veníamos hace tiempo tratando de tensionar para que pasara algo asì). En este sentido, se sienten protagonistas del proceso, pese a que, como a todos, los sorprendió. Ramón, militante político, nos cuenta con mucho entusiasmo que quiere estar presente en cada manifestación para poder contarles a sus hijos, en un futuro imaginado, que fue parte importante de esta transformación:

Me acuerdo de un caballero que salió con un cartelito (...) que decía «El día siguiente de la revolución, tú deseas cómo deseas vivirlo» y habían batucadas y me pongo a ver a los paraderos y toda la gente bailando, celebrando. Entonces en mi mente me dije «sí, así lo quería vivir». No quería estar en la casa, yo quería estar ahí. (Ramón, 22 años, militante político).

Ahora bien, pese al entusiasmo de Ramón, Ariel y Salvador organizador de una asamblea territorial periférica e hijo de militantes de izquierda - son más críticos, señalando cómo la falta de capital político de la población en general, especialmente de los jóvenes, se traduce en una movilización expresiva, sin un proyecto político de transformación claro.

Mi gran crítica al estallido social que espero que se solucione, es que suele ser muy de emociones, muy de enojo, muy descontento, pero exceptuando a aquellas organizaciones que van a las manifestaciones (...), no hay un contenido concreto, no hay un proyecto y ese es el temor que también tengo. (Salvador, 26 años, activista social).

Esto lo observan, por una parte, en el compromiso de los jóvenes con la violencia contra la policía. Esto no quiere decir que rechacen la violencia, al contrario, tienden a legitimarla, pero consideran que la transformación de las instituciones responde a un proyecto de más largo plazo que el enfrentamiento directo. Por otra, observan poca conexión entre el Estallido Social y las ollas comunes que se desplegaron en las poblaciones. Para ellos, este último fenómeno responde más a una lógica de necesidad y solidaridad local que a una organización política propiamente tal, debido, en parte, a la diversidad de actores que convocan, participando militantes, miembros de iglesias y vecinos particulares, entre otros. Incluso, Ariel destaca que las ollas comunes han 
permitido que los municipios de derecha reactiven su capital político a partir del apoyo a estas instancias.

En relación con los saqueos, Ramón, al igual que los otros jóvenes, comparte su crítica hacia las formas «desviadas» de practicarlo, es decir, aquellos que saqueaban artículos electrónicos en vez de alimentos («la tele a la barricada»), o que atacaban pequeños almacenes en lugar de grandes cadenas de supermercados o farmacias. Al contrario, valora las prácticas redistributivas entre quienes saqueaban. Sin embargo, a diferencia de la mayoría de los entrevistados, suma a esta «economía moral» (Fassin, 2009) del saqueo, un marco político para interpretarlo, dentro del cual las prácticas de saqueo son interpretadas como una forma de «recuperación», reactivando la clave con la cual se promovieron estas prácticas en la década de 1980 entre agrupaciones de izquierda.

Ariel y Salvador, en cambio, no atribuyen un significado político a los saqueos, pero tampoco los condenan. En este sentido, descartan que hayan sido bandas de narcotraficantes quienes hayan liderado los desvalijamientos, atribuyendo esta práctica a sus propios vecinos e incluso familiares, los cuales habrían actuado a partir de la «oportunidad» o motivados por la lógica expresiva que orientaría el Estallido Social y la violencia.

Respecto a las asambleas territoriales y cabildos que surgieron a propósito del estallido, todos tuvieron una participación muy activa. En el caso de Ramón, cuya entrevista fue realizada en diciembre de 2019 , estaba muy esperanzado en el rol que tendrían estas organizaciones en la rearticulación del tejido popular. Sin embargo, en el caso de Ariel y Salvador, entrevistados a más de seis meses del Estallido Social, consideran que ese evento social y político extraordinario permitió la emergencia de muchas instancias de organización, las cuales, además de estar compuestas por individuos con poca formación política, no generaron mayor interés en los vecinos, especialmente entre los más jóvenes, por lo que se han ido debilitando con el paso del tiempo y los efectos de la pandemia. Ariel valora de estas organizaciones una nueva forma de relacionarse con sus compañeros y vecinos, donde prima una sincera preocupación y afecto, sin asistencialismo («más cariño, es más humano, más preocupado de la persona»).

Pese a este análisis pesimista en relación con los niveles de organización y conciencia política alcanzados tras el Estallido Social, estos jóvenes militantes se muestran relativamente optimistas de cara al proceso constitucional en curso. En general, todos critican la forma en que se logró el acuerdo («les faltó el respeto a todos») y desconfían de las reales posibilidades de cambio que abre este 
proceso, sin embargo, ninguno se resta de participar. Por redes sociales, pudimos observar cómo Ariel, junto a la organización social que levantó, organizaba actos de campaña a favor del «Apruebo». En el caso de Salvador, único entrevistado postplebiscito, narra con mucha emoción la celebración del triunfo del «Apruebo» en su población: los vecinos del pasaje se reunieron alrededor de una barricada, cantando, mientras una niña corría con una foto de Salvador Allende. Para él, hijo de militantes de izquierda, como insinúa su nombre, en ese momento no pudo contener la emoción: «Como que llegó una esperanza a mi corazón».

\section{REFLEXIONES FINALES}

El Estallido Social de Octubre ha sido interpretado, por algunos intelectuales ${ }^{15}$, como una convulsión espasmódica, emocional y violenta, carente de cualquier sentido ciudadano o político. En ese contexto, no pocos recurrieron al concepto decimonónico de anomia para explicar la revuelta urbana, como bien critican Ganter y Zarzuri (2020). Tales descriptores ganaban mayor fuerza a la hora de describir la participación de jóvenes populares. Después de años de discusión sobre su apatía política, la irrupción en Plaza Dignidad de jóvenes periféricos ${ }^{16}$, por ejemplo, congregados con sus hinchadas de fútbol, causó gran resquemor. En ese contexto, la policía reforzó sus criterios de racismo y clasismo, descargando su violencia contra los cuerpos juveniles populares.

Como se planteó en este artículo, la participación de los jóvenes populares no se limitó a las movilizaciones en el centro, locus tradicional de la protesta en Santiago. Las calles y avenidas de poblaciones y comunas estigmatizadas se convirtieron en escenario para la reivindicación colectiva del derecho a una vida digna. Este inédito descentramiento de las protestas - que transformó, por ejemplo, a la Plaza de Maipú y de Puente Alto en hitos para miles de

${ }^{15}$ Por ejemplo, revisar Carlos Peña: «No creo haberme equivocado absolutamente en nada», entrevista en La Tercera, 4 de enero de 2020, en: https://www.latercera.com/la-tercera-domingo/noticia/carlos-pena-no-creo-habermeequivocado-absolutamente-nada/961001/

${ }^{16}$ En la Encuesta Zona Zero, realizada por el Núcleo de Sociología Contingente de la Universidad de Chile (NUDESOC), los resultados indican que la mayor cantidad de manifestantes de Plaza Dignidad eran adultos jóvenes, provenientes de comunas no aledañas a Santiago Centro. Cabe destacar aquí que un 7,4\% de los encuestados pertenecía a Puente Alto y un 7\% a Maipú, siendo solo superados por Santiago Centro $(12,8 \%)$ y Ñuñoa $(8,3 \%)$. 
manifestantes - obliga a repensar una vez más las formas de participación política de los sectores populares.

Sobre esta apropiación popular de los espacios periféricos, quisiéramos volver a los estudios urbanos. Desde los años 2000, fueron múltiples las investigaciones que, desde este campo, analizaron las poblaciones y villas de la periferia de Santiago, para discutir sobre los efectos perversos de la segregación sociorresidencial. Frente a la ausencia de movimientos u organizaciones de pobladores que lograran visibilidad a nivel nacional, estas investigaciones destacaron la falta de cohesión social, de sentido comunitario, historia común o participación. Ante este escenario, optaron por importar los diagnósticos realizados en Estados Unidos a propósito de la nueva pobreza urbana, subrayando la guetización de los barrios populares. Ahora bien, tal como destaca Caldeira a propósito del trabajo de Wacquant (2007), la crisis del mundo obrero no significa que no surjan otras formas de dignidad en el mundo popular. Al contrario, los estudios sobre juventud, en territorios con las mismas condiciones, advirtieron un intenso proceso de repolitización de la vida cotidiana, donde los primeros no percibían más que desolación, desesperanza y, sobre todo, incapacidad de articulación de demandas colectivas y de un sentido común. De esta forma, se abre nuevamente la pregunta respecto a la subjetividad política de los jóvenes populares.

Sin embargo, vale decir que la focalización sobre los colectivos contraculturales trae sus propios desafíos, entre ellos, la pregunta por los límites políticos de los discursos y prácticas contraculturales de los jóvenes populares. Ante la emergencia de nuevas formas de participación juveniles, Reguillo (2012: 36) advierte la importancia de no perder de vista las capacidades de negociación con la política institucional que desarrollan algunos colectivos juveniles, por ejemplo, por medio de asignación de fondos públicos, así como las tensiones en sus propias prácticas y discursos que, a veces, pueden llegar a reproducir lógicas de poder que critican de la política hegemónica.

Un problema de las lecturas «neotribalistas», debate Muñoz (2006: 136), es cómo la dimensión del conflicto queda de cierta forma excluida de esos análisis, al sobredimensionar la cohesión interna de los grupos bajo criterios estéticos y éticos, sin profundizar en las dimensiones institucionales, el papel del mercado y los antagonismos políticos que atraviesan a estas experiencias de participación y activismo. Esto, en parte, se debe a una sobrevaloración del presentismo, agrega Muñoz, que desestima las dimensiones sociohistóricas. 
Para cerrar, y parafraseando al antropólogo egipcio Asef Bayat (2015), cabe la pregunta de si en Santiago estuvimos frente a uno o a varios estallidos sociales. Esa interrogación implica discutir sobre las posibles especificidades de la revuelta en los territorios habitados por los jóvenes que presentamos en este artículo. En ese marco, y pensando en las advertencias de Muñoz (2006), algo que queda pendiente es examinar si hubo o no conexiones entre el proceso de rearticulación del movimiento de pobladores y el surgimiento de partidos políticos de base popular, como Igualdad, con los acontecimientos de octubre. Entender esas relaciones y el impacto de esas experiencias y trayectorias de participación popular resulta clave y debe ser mejor estudiado. Lo mismo cabe interrogar sobre la acumulación de prácticas de auto-organización y acción directa de los cientos de colectivos contraculturales y políticos que, con distintas duraciones y extensiones, han emergido en las poblaciones de Santiago a lo largo de toda la transición democrática. Todo esto permitiría cualificar la idea de «estallido», al situar las múltiples experiencias y procesos de este ciclo contencioso en una trama sociohistórica y política densa y de larga data.

RECIBIDO: 18 DE ENERO DE 2021

ACEPTADO: 21 DE ENERO DE 2021 


\section{BIBLIOGRAFÍA}

AguilerA, Ó. y MuÑoz, V. (2015). Preguntas por la juventud, preguntas por la política. Acción colectiva, movimientos sociales y militancia en los estudios de juventud. Chile 1967-973. En P. COTTET (Ed.), Juventudes. Metáforas del Chile contemporáneo. Santiago de Chile: Ril editores.

Angelcos, N. (2016). Movimiento de pobladores. Lucha social y política en el Chile Contemporáneo. Educação em perspectiva, 7(2), 324-345.

Angelcos, N. y PÉREz, M. (2017). De la «desaparición» a la reemergencia: Continuidades y rupturas del movimiento de pobladores en Chile. Latin American Research Review, 52(1).

Angelcos, N., Jordana, C. y Sandoval, C. (2019). Sólo en el pueblo confiamos: la estructura moral del discurso político radical de los pobladores en el Partido Igualdad. Izquierdas, 46, 22-46.

BAdE, G. (2004). Puro verso es tu Chile en la pobla... Nosotros los chilenos, 5, 62-89.

BADILla, M. (2020). Memorias urbanas en la periferia de Santiago. Develando violencias y resistencias en la ciudad. Persona y Sociedad, 34(1), 137157.

Bargsted, M. y Delgado, C. (2012). Cambios y continuidades en la participación electoral del plebiscito del 25 de octubre. Ciper, 09/01/21.

Disponible en: https://www.ciperchile.cl/2021/01/09/cambios-ycontinuidades-en-la-participacion-electoral-del-plebiscito-del-25-deoctubre/

BAyAt, A. (2015). Plebeians of the Arab Spring. Current Anthropology, 56(S11), S33-S43. doi:10.1086/681523

Bertaux, D. (2005). Los relatos de vida. Perspectiva etnosociológica. Barcelona: Ediciones Bellaterra.

BOURGOIS, P. (1995). In search of respect: selling crack in El barrio. Cambridge, UK: Cambridge University Press.

CALDEIRA, T. (2009). Marginality, again?! International Journal of Urban and Regional Research, 33(3), 848-853.

. (2010). Espacio, segregación y arte urbano en el Brasil. Buenos Aires: Katz Editores.

Cammaerts, B., Bruter, M., Banaji, S., Harrison, S. y Anstead, N. (2014). The myth of youth apathy: Young Europeans' critical attitudes toward democratic life. American Behavioral Scientist, 58(5), 645-664.

Correa, J. B. y MANRÍQUEZ, M. S. (2009). Nuevas prácticas políticas en jóvenes de Chile: conocimientos acumulados 2000-2008. Revista 
Latinoamericana de Ciencias Sociales, Niñez y Juventud, 7(2), 13791403.

DuBET, F. (1987a). La galère: jeunes en survie. París: Fayard.

- (1987b). Las conductas marginales de los jóvenes pobladores. Proposiciones, 14, 94-100.

Engel, E., Gómez, C., Pardow, D. y Simonetti, P. (2020). Informe sobre la evolución de la epidemia de covid-19 en Chile (29 de octubre de 2020). Espacio Público.

FASsin, D. (2009). Les économies morales revisitées. Annales. Histoire, Sciences Sociales, 6, 1237-1266.

GamboA, A. (2005). (No) Queremos Ciudadanía. Una mirada a la ciudadanía desde tres organizaciones sociales juveniles. ECO, Educación y Comunicaciones (Santiago).

GANTER, R. y ZARZURI, R. (2020). Rapsodia para una revuelta social: retazos narrativos y expresiones generacionales del 18-O en el Chile actual. Universum (Talca), 35(1), 74-103.

GoICOVIC, I. (2000). Del control social a la política social. La conflictiva relación entre los jóvenes populares y el Estado en la historia de Chile. Última Década, 8(12), 103-123.

KITANOVA, M. (2019). Youth political participation in the EU: evidence from a cross-national analysis. Journal of Youth Studies, 23(7), 819-836. doi: 10.1080/13676261.2019.1636951

LAGOS, M. (2017). El canto de los que sobran: ética y relaciones socio-creativas de la música independiente: Santiago, 2007-2017. Tesis para optar al grado de Licenciado en Historia, Universidad de Chile, Santiago. http://repositorio.uchile.cl/handle/2250/146613

LAMONT, M. y BAIL, C. (2005). Sur les frontières de la reconnaissance. Les catégories internes et externes de l'identité collective. Revue européenne de migrations internationales, 21(2), 61-90.

Martínez, J. y Palacios, M. (1996). Informe sobre la decencia. Santiago de Chile: Ediciones Sur.

MuÑOZ, V. (2002). Movimiento social juvenil y eje cultural: Dos contextos de reconstrucción organizativa (1976-1982/1989-2002). Última Ddécada, 10(17), 41-64. https://dx.doi.org/10.4067/S0718-22362002000200003 . (2006). Condiciones «Post» y Asociatividad Juvenil: Preguntas por lo Político en México y Chile. Última Década, 14(25), 113-141. 
Moraga, M. y Solorzano, H. (2005). Cultura urbana hip-hop. Movimiento contracultural emergente en los jóvenes de Iquique. Última Década, 13(23), 77-101.

Núcleo de Sociología Contingente [NUDESOC]. (2020). Informe de resultados oficial Encuesta Zona Cero. Recuperado de: www.nudesoc.cl

Poch, P. (2009). Del Mensaje a la Acción: Construyendo el Movimiento HipHop en Chile (1984-2008). Tesis para optar al grado de Licenciado en Historia. Universidad de Chile, Santiago. http://repositorio.uchile.cl/handle/2250/109797

Redolés, S. y Pedreros, P. (2011). No cantamos por cantar. Prácticas autogestionarias de los músicos populares, Santiago 2000-2010. Tesis para optar al grado de Licenciado en Historia. Universidad de Chile, Facultad de Filosofía y Humanidades, Santiago.

Reguillo, R. (2012). Culturas juveniles. Formas políticas del desencanto. Buenos Aires: Siglo Veintiuno.

REYES, C. (2011). Una patada en la cara. El punk como contra-cultura. Santiago desde los ochenta a la actualidad. Tesis para optar al grado de Licenciado en Historia. Universidad de Chile, Facultad de Filosofía y Humanidades, Santiago.

SABAtini, F., CÁCERES, G. y CERDA, J. (2001). Segregación residencial en las principales ciudades chilenas: tendencias de las tres últimas décadas y posibles cursos de acción. EURE, 27(82), 21-42.

SABATINI, F. y Wormald, G. (2004). La guerra de la basura de Santiago: desde el derecho a la vivienda al derecho a la ciudad. EURE, 30(91), 67-86.

SAlAZAR, G. (2012). Movimientos sociales en Chile: Trayectoria histórica y proyección política (Vol. 3). Santiago de Chile: Uqbar.

SAlCEDO, R. y RASSE, A. (2012). The heterogeneous nature of urban poor families. City \& Community, 11(1), 94-118.

SMALl, M. (2007). Is there such a thing as «the ghetto»? City: analysis of urban trends, culture, theory, policy, action, 11(3), 413-421. http://dx.doi.org/10.1080/13604810701669173

Tijoux, M. E., Facuse, M. y Urrutia, M. (2012). El Hip Hop: ¿Arte popular de lo cotidiano o resistencia táctica a la marginación? Polis. Revista Latinoamericana, 11(33), 429-450.

TIRONI, M. (2003). Nueva pobreza urbana: vivienda y capital social en Santiago de Chile, 1985-2001. Santiago de Chile: Universidad de Chile, Predes/Ril Editores.

VALENZUElA, E. (1984). La rebelión de los jóvenes (un estudio sobre anomia social). Santiago de Chile: Ediciones Sur. 
VALENZUELA, K. (2007). Colectivos juveniles: ¿inmadurez política o afirmación de otras políticas posibles? Última Década, 15(26), 31-52. https://dx.doi.org/10.4067/S0718-22362007000100003

Venegas, J. (2016). ¿Por qué los jóvenes chilenos rechazan la política? Desafección política juvenil en el Chile postransición. Santiago de Chile: Ril Editores.

Verba, S., Schlozman, K. y Brady, H. (1995). Voice and equality: civic voluntarism in american politics. Cambridge, MA: Harvard University Press.

WACQUANT, L. (2007). Urban outcasts: A comparative sociology of advanced marginality. Cambridge: Polity Press.

Wacquant, L., Slater, T. y Pereira, V. B. (2014). Territorial stigmatization in action. Environment and planning A, 46(6), 1270-1280.

ZARZURI, R. y GANTER, R. (2002). Memoria, cultura y nuevas narrativas juveniles. Santiago de Chile: Centro de Estudios Socioculturales. 